Economia e Sociedade, Campinas, Unicamp. IE.

http://dx.doi.org/10.1590/1982-3533.2020v30n1art09

\title{
Mensurar o trabalho não pago no Brasil: uma proposta metodológica *
}

\author{
Hildete Pereira de Melo ** \\ Lucilene Morandi ${ }^{* * *}$
}

\begin{abstract}
Resumo
As estatísticas mostram que, em todo o mundo, as mulheres são as maiores responsáveis pelo trabalho de reprodução da vida humana, que envolve as tarefas domésticas e de cuidados, definido como trabalho não pago. É preciso que se reconheça seu valor e importância para a sociedade. Uma forma de fazer isso é mostrar o volume de riqueza, na forma de bens e serviços, gerados por esse trabalho invisível, através de sua mensuração/valoração. Para isso, é necessária a criação de uma Conta Satélite do trabalho não-pago, cumprindo um dos objetivos propostos pela ONU na lista de Metas para o Milênio. Desta forma, este estudo propõe a discussão de um indicador social do trabalho não pago para o Brasil a ser incorporado às Contas Nacionais. Este trabalho discute o significado das Contas Satélites para as estatísticas de gênero, realçando a importância econômica dos afazeres domésticos e cuidados, não apenas para as famílias mas para a sociedade como um todo, destacando as dificuldades em conciliar trabalho e família para as pessoas responsáveis pelo trabalho não pago. Por fim, o texto desenvolve uma proposta metodológica para estimar o trabalho não-pago no Brasil compatível com a metodologia das contas nacionais.
\end{abstract}

Palavras-chave: Divisão sexual do trabalho, PIB, Contas Satélites, Macroeconomia de gênero.

\section{Abstract \\ Measuring unpaid work in Brazil: a methodological proposal}

Statistics show that, worldwide, women are the most responsible for the reproductive work of human life, which involves domestic tasks and care giving, and is defined as unpaid work. It is necessary to recognize the value and importance for society of this work. One way of doing this is to show the volume of wealth, in the form of goods and services, generated by this invisible work, through its measurement/valuation. For this, a Satellite Account of unpaid work is created, fulfilling one of the objectives proposed by the UN in the list of Millennium Development Goals. Thus, this study proposes a social indicator of unpaid work for Brazil to be incorporated into the national accounts system. This paper discusses the meaning of Satellite Accounts for gender statistics, highlighting the economic importance of household chores and care giving, not only for families but for society as a whole, emphasizing the difficulties in reconciling work and family for those responsible for this unpaid work. Finally, the text develops a methodological proposal to estimate unpaid work in Brazil that is compatible with national accounting.

Keywords: Sexual division of labor, GDP; Satellite Accounts, Gender macroeconomics. JEL E01, E24.

As estatísticas sobre a participação das mulheres no mercado de trabalho pago (United Nations, 2016) mostram que a participação das mulheres na força de trabalho é proporcionalmente menor que a dos homens; as mulheres estão mais presentes nos setores produtivos que apresentam menor remuneração e piores coberturas sociais; as mulheres ganham cerca de $30 \%$ menos que os

\footnotetext{
* Artigo recebido em 3 de outubro de 2018 e aprovado em 29 de maio de 2020. Uma versão preliminar deste trabalho foi apresentada no 56 . ICA Congreso Internacional de Americanistas, realizado em julho de 2018, em Salamanca, Espanha.

** Professora da Universidade Federal Fluminense (UFF), Niterói, RJ, Brasil. E-mail: hildete43@gmail.com. ORCiD: https://orcid.org/0000-0002-9701-7890,

${ }^{* * *}$ Professora da Universidade Federal Fluminense (UFF), Niterói, RJ, Brasil. E-mail: imorandi@id.uff.br. ORCiD: https://orcid.org/0000-0002-3943-6229,
} 
homens, mesmo com cargos e qualificação semelhantes, e assumem menos cargos de chefia e gerência que os homens.

As estatísticas também mostram que as mulheres são as maiores responsáveis pelo trabalho não pago - trabalho realizado no interior das famílias em prol de seus membros -, e também são as responsáveis pela reprodução da vida humana. As tarefas envolvidas nessas funções demandam tempo, deixando as mulheres com desvantagem em relação aos homens no mercado de trabalho pago.

O reconhecimento desta discriminação não é de agora, e está na raiz da explosão dos movimentos feministas, principalmente a partir da metade do século XX. A publicação do livro $(O$ segundo sexo) de Simone Beauvoir em 1949, na França, provocou o debate sobre a subalternidade feminina na sociedade, mas o avanço mais significativo se deu com a denúncia de Betty Friedan sobre o não reconhecimento da importância social dos trabalhos doméstico e de cuidados, relativos à reprodução da vida, no seu livro (A mística feminina), publicado em 1963 nos EUA. Friedan discutia a alienação, a desvalorização e a dependência vividas pelas mulheres da classe média americana, já naquela década mais escolarizadas e reduzidas a uma vida submissa aos maridos nos subúrbios do País. Em sua pesquisa, Friedan demonstrou que a carga dos trabalhos domésticos trazia insatisfação às mulheres porque as impedia ou dificultava sua entrada no mercado de trabalho e sua independência econômica, o que gerava o "mal sem nome" como ficou denominada genericamente uma doença que causava danos físicos e psíquicos em muitas mulheres dos subúrbios (classe média) à época, mas que não era identificada com nenhum mal conhecido. Na verdade, era a exteriorização da insatisfação dessas mulheres. Como conclusão de sua análise, Friedan pregava que as mulheres deviam buscar sua autonomia econômica através da ida para o mercado de trabalho, embora isso implicasse no custo de acumularem jornadas de trabalho: o trabalho externo e o trabalho interno de tarefas domésticas e de cuidados com a família. Essas ideias tiveram grande repercussão e incentivou as mulheres a organizarem movimentos e manifestações feministas nos EUA, sobretudo no interior dos campos universitários, que rapidamente se alastraram pela Europa (Michel, 1977) ${ }^{1}$.

Embora as mulheres estivessem conscientes da carga dupla de trabalho, acrescentando à carga do trabalho remunerado os cuidados das crianças e da família, não havia nenhuma estatística sobre o valor da produção gerada por este trabalho nem nenhuma discussão ainda sobre as consequências, para as mulheres, da responsabilidade pelo trabalho doméstico e de cuidados, que reduzia as possibilidades de suas jornadas com o trabalho pago para serem apenas donas de casa (Oakley, 1990). No entanto, a contribuição deste trabalho, realizado por mulheres (em sua grande maioria), bem como homens e crianças não assalariadas, é fundamental para definir os padrões de qualidade de vida e de sua reprodução e tem, mesmo que não visível nas estatísticas, um valor econômico e social para a família, para as empresas e para a nação. Pois, se o Produto Interno Bruto (PIB) e a Renda Nacional são índices fundamentais para as decisões econômicas, a omissão do valor dos bens e serviços gerados pelo trabalho não pago causa distorções nas estatísticas econômicas e nas decisões de políticas econômicas. A não inclusão do valor dessas tarefas domésticas e cuidados nos indicadores

(1) No Brasil, em 1978, a professora Neuma Aguiar organizou um seminário internacional no Instituto Universitário de Pesquisas do Rio de Janeiro (IUPERJ) e que teve o apoio da Associação de Pesquisas e Estudos sobre a Mulher (APEM), que teve como tema a perspectiva da identificação e codificação das atividades domésticas realizadas no contexto da casa. (Aguiar, 1984. Ver especialmente o capítulo de E. A, Ceborarev, "As atividades do tempo de atividades domésticas e não-domésticas de mulheres camponesas na América Latina"). 
econômicos torna a política econômica discriminatória em relação às mulheres, consideradas mãode-obra secundária. E, por outro lado, a dificuldade em mensurar o valor deste trabalho não justifica a sua não inclusão nas estatísticas macroeconômicas oficiais, sobretudo depois dos enormes progressos nos métodos estatísticos e nas análises quantitativas dos dados econômicos (Walker, 1977).

É fundamental que a sociedade reconheça a importância do trabalho reprodutivo realizado pelas mulheres, não pago além de homens e crianças. Mas, para que se reconheça o valor e sua importância para a sociedade, é necessário dar visibilidade a esse trabalho através de sua mensuração. Para Walker (1977, p. 176-177), ninguém tem dúvidas que são as mulheres que fazem estes trabalhos, sejam elas donas-de-casa ou trabalhadoras/ profissionais no mundo do trabalho. Mensurar e incluir o valor da produção dos afazeres domésticos e cuidados no valor do PIB é uma decisão mais política que uma impossibilidade técnica.

No Brasil, nos anos 1970 e 1980, as cientistas sociais Cristina Bruschini, Alice de Paiva Abreu, Leila González, Neuma Aguiar, entre outras, desenvolveram pesquisas sobre desigualdade e discriminação no mercado de trabalho. As feministas economistas enfrentavam enormes dificuldades para iniciar este campo de investigação no interior da teoria econômica, que considera produto apenas os bens e serviços que são comercializados no mercado (Melo; Serrano, 1997, p. 138), e não considera em suas análises o trabalho doméstico e de cuidados, apesar de ser absolutamente necessário para a reprodução da vida e para a manutenção da qualidade de vida (Carrasco, 2012). Nos últimos trinta anos emergiram novos estudos e pesquisas sobre a divisão sexual do trabalho (incluindo pesquisas sobre o uso do tempo e as diferenças relativas a gênero no mercado de trabalho), com destaque para os trabalhos de Antonella Piccio, Cristina Carrasco, Danielle Kergoat, Helena Hirata, Lourdes Bendeira, Maria Angeles Duran e outras, que têm mantido e ampliado estas discussões, tanto no âmbito do debate acadêmico quanto do político.

No início dos anos 2000, a publicação pela Pesquisa Nacional por Amostra de Domicílios (PNAD/IBGE) de uma variável relativa ao tempo dispendido pelas pessoas, acima de 10 anos de idade, nas atividades relativas aos afazeres domésticos e cuidados, possibilitou que a discussão sobre divisão sexual do trabalho e seu impacto sobre a renda das mulheres pudesse ir adiante no Brasil. Estas informações abriram novas oportunidades de pesquisa e análise sobre o trabalho não pago realizado pelas mulheres no interior das famílias e propôs uma discussão sobre a distribuição do tempo necessário para a realização dos afazeres domésticos entre homens e mulheres, propondo um indicador para a mensuração do valor gerado por este trabalho como proporção do PIB brasileiro (Melo; Considera; Sabbato, 2007).

Na segunda metade dos anos 2000, com o apoio da Secretaria de Políticas para as Mulheres da Presidência da República, em conjunto com IBGE, foi desenhada e aplicada uma pesquisa-piloto sobre uso do tempo. A pesquisa sobre uso do tempo é essencial para a mensuração (valoração) do trabalho não pago (afazeres domésticos e cuidados), permitindo a visibilização do trabalho não pago e a definição de políticas públicas de combate às desigualdades de gênero (Santos; Simões, 2018; Saboia; Soares, 2007).

A luta das mulheres e dos movimentos feministas em todo o mundo lograram avanços importantes, como a proposição pela Organização das Nações Unidas (ONU), responsável pela 
definição da metodologia usada pelos países para a mensuração do produto agregado (PIB), da criação de uma conta satélite do trabalho não remunerado. A conta satélite é a forma estatisticamente coerente para a incorporação do valor do trabalho não pago no valor do PIB, sem criar distorções no Sistema de Contas Nacionais. A criação, pelos países, de uma conta satélite do trabalho não pago é parte dos objetivos propostos pela ONU como metas para o milênio (ONU, 2015; 2016). A criação da conta satélite do trabalho não pago está coerente com o objetivo de reduzir as desigualdades de gênero, eliminando as diferenças de rendimento entre homens e mulheres no mercado de trabalho quando ocupam postos semelhantes, e aumentando a participação feminina no mercado de trabalho, reduzindo sua dependência econômica. O resultado é um maior empoderamento das mulheres, melhorando sua capacidade de buscar por seus direitos.

Este estudo propõe a discussão de um indicador social do trabalho não pago para o Brasil, a ser incorporado ao Sistema de Contas Nacionais ( $\mathrm{SCN}$ ) através de conta satélite, seguindo a recomendação da ONU nos seus Objetivos do Milênio 2030². Ao indicar a incorporação da conta satélite, a ONU reconhece a importância das políticas públicas como ferramenta importante para a redução das desigualdades, inclusive a desigualdade de gênero. Como as definições de políticas públicas utilizam os dados das Contas Nacionais para a análise e tomada de decisão, a inclusão do valor do produto gerado pelo trabalho não pago, bem como a visibilidade do tempo necessário para sua realização (disponível através das pesquisas de uso do tempo), possibilitam que as decisões de política econômica sejam mais ajustadas à realidade e deixem de ser viesadas, como é hoje.

A medida do crescimento e do desenvolvimento econômico vai além da contabilização do Produto Interno Bruto (PIB), que se restringe à medição da produção de bens e serviços para o mercado porque, como destaca Teixeira, "só há desenvolvimento quando os benefícios do crescimento econômico servem à ampliação da capacidade dos seres humanos" (2012, p. 15) para decidirem e fazerem o melhor para suas vidas. As capacidades humanas devem ser entendidas como a possibilidade de vida longa e saudável, acesso a instrução, a condições materiais satisfatórias, e ser capaz e poder participar da vida da comunidade.

É neste contexto que apresentamos a proposta de discussão da criação de um indicador do trabalho não pago para o Brasil. O objetivo é que este indicador seja capaz de mostrar as diferenças relacionadas a sexo nas estatísticas macroeconômicas, servindo, dessa forma, como um indicador mais realista para a análise dos objetivos e impactos das políticas econômicas sobre áreas prioritárias, como saúde, educação e emprego. Entende-se que um indicador macroeconômico, complementar à medição do PIB, é capaz de mensurar e representar melhor as desigualdades das relações de gênero, permitindo a adoção de políticas públicas mais adequadas e eficientes para promoverem, senão a extinção, pelo menos a redução dessas desigualdades, adequando o Brasil aos Objetivos do Milênio propostos pela ONU.

Este trabalho está estruturado da seguinte forma: além dessa introdução, discute o significado das Contas Satélites para as estatísticas de gênero, realçando a importância dos afazeres domésticos e cuidados para o bem-estar das famílias e para a disponibilidade de mão de obra para o mercado de

(2) Ao descrever o Objetivo 5, Igualdade de Gênero, especifica no item 5.c "Adotar e fortalecer políticas sólidas e legislação aplicável para a promoção da igualdade de gênero e o empoderamento de todas as mulheres e meninas em todos os níveis" (United Nations, 2015, p. 22). 
trabalho, destacando as dificuldades ou impossibilidade de conciliar trabalho remunerado e trabalho não pago para as pessoas responsáveis pelos afazeres domésticos e os cuidados dentro da família. Em seguida, apresenta uma breve resenha sobre as propostas metodológicas internacionais e nacionais e desenvolve uma proposta metodológica para estimar o trabalho não pago no Brasil, compatível com a metodologia das contas nacionais. Por fim, são apresentadas as considerações finais.

\section{O significado das contas satélites para as estatísticas de gênero}

O Sistema de Contas Nacionais ( $\mathrm{SCN}$ ), tem como "objetivo bem estabelecido: a partir de um marco estrutural teórico, apresentar recomendações de como obter os dados para quantificar esse marco" (Feijó; Ramos, 2008, p. 3), cujo principal indicador é o PIB. A metodologia para o cálculo das variáveis que compõem o SCN foi criada em consonância com a teoria econômica e evolui com ela, além de, ao longo do tempo, sofrer alterações com o intuito de incorporar os avanços tecnológicos e estatísticos que permitam melhorar a coleta e o tratamento dos dados. O SCN é a fonte mais importante para as análises macroeconômicas, por ser abrangente e manter regularidade metodológica, permitindo comparações temporais e entre países. As análises econômicas usam as estatísticas da SCN para melhor compreender as relações econômicas, avaliar e propor soluções para resultados não satisfatórios da atividade econômica, como os relativos aos níveis de renda, produto, emprego, preços e salários. Pode-se concluir assim que as estatísticas das Contas Nacionais são a base das decisões das políticas econômicas dos países.

O PIB é uma estatística agregada da riqueza gerada no país num determinado período, mas que, no seu formato atual, não permite estudos macroeconômicos com corte de gênero, cor/raça, apesar de pesquisas mostrarem que há diferenças importantes quando estas características são utilizadas para análises de rendimentos e oportunidades no mercado de trabalho ${ }^{3}$. Além disso, o PIB também não contabiliza o valor da produção gerada pelas atividades não-mercantis realizadas no interior das famílias para a reprodução da vida e melhoria da qualidade de vida de seus membros. A forma de se contornar essa deficiência, defendida pelas Nações Unidas ${ }^{4}$, é através da incorporação da conta satélite do trabalho não pago.

As contas satélites são "uma extensão do Sistema de Contas Nacionais [e] [...] foram criadas para expandir a capacidade de análise das Contas Nacionais sobre determinadas áreas" (IBGE, 2009, p. 5). Elas permitem a análise de setores produtivos específicos, de forma coerente aos demais dados, aumentando o detalhamento e o escopo dos setores em estudo.

No SCN, a produção doméstica de serviços para consumo próprio da família é denominada trabalho não pago e consiste basicamente dos afazeres domésticos e dos cuidados com as pessoas, incluindo as tarefas de: preparar comida, lavar louça, fazer limpeza e manutenção da casa, lavar e passar roupa, jardinagem, atividades de subsistência como buscar água e lenha, cuidar de animais domésticos, fazer compras, fazer instalação e reparo na habitação e em aparelhos domésticos, cuidar das crianças e cuidar de membros da família doentes, idosos ou com alguma incapacidade temporária ou permanente. Além dessas atividades, também é considerado trabalho não pago o trabalho

(3) Ver também: Melo, Considera e Sabbato (2007, 2016); Morandi, Melo e Dweck (2018); Jesus (2018).

(4) Declaração e Plataforma de Ação de Pequim (ONU, 1995). 
voluntário ou comunitário, realizado em organizações e órgãos da comunidade ou a ajuda informal a outros membros da comunidade.

Essas atividades são fundamentais para a reprodução da vida, para gerar e garantir bem-estar e qualidade de vida aos membros da família, além de ser imprescindível para garantir a disponibilidade de mão de obra para as empresas em atividades remuneradas. Para que alguém esteja disponível em atividades remuneradas no mercado, alguém tem que cuidar das crianças, cuidar da alimentação, da roupa e da casa de forma adequada. Acrescente-se a isso o fato de o trabalho não pago ser um substituto dos gastos públicos em creches, instituições de cuidados e escolas de tempo integral. Os cuidados dispensados pelas famílias a crianças, idosos e enfermos substitui a necessidade de o Estado disponibilizar esses serviços.

As estatísticas mostram que são as mulheres as principais responsáveis pelo trabalho não pago no mundo. Por outro lado, os dados também mostram que as mulheres não participam em igualdade de condições com os homens no mercado de trabalho remunerado (Troncoso, 2012). Na média, elas recebem menos que os homens, mesmo quando estão em postos de trabalho e têm formação similares. Ao mesmo tempo, as mulheres estão em maior percentagem que os homens em cargos com contratos informais e condições de trabalho mais precárias, além de estarem mais expostas que os homens à violência física e/ou sexual. Esse quadro é ainda mais grave para as mulheres de classes mais pobres, sujeitas ainda a discriminações relativas à raça, etnia e/ou estado civil (Melo; Thomé, 2018, cap. 6).

Os governos nacionais são responsáveis pela promoção da redução da desigualdade de gênero e devem garantir às mulheres seus direitos. Para isso, é fundamental a atualização e modernização das leis, acompanhando as diretrizes acordadas pelas convenções internacionais. Mas a promoção da igualdade de gênero requer mais que leis. A definição dos objetivos de política pública e econômica tem papel importante porque pode garantir oferta de serviços públicos de qualidade e em número suficiente - como creches e escolas de tempo integral ${ }^{5}$ e centros de atendimentos para idosos e/ou doentes -, promovendo a redução das desigualdades, incluindo a de gênero. Exemplos de políticas públicas que reduzem a desigualdade são: expansão do serviço de fornecimento de água potável para todas as unidades residenciais, que em regiões mais pobres pode representar redução significativa de tempo gasto por meninas e mulheres na atividade de buscar água, e disponibilização de mais e melhores creches públicas, garantindo à mulher o direito e a tranquilidade de participar do mercado de trabalho pago em igualdade de condições (Jain-Chandra et al., 2018).

A preferência por diretrizes de políticas públicas de viés socioeconômico no orçamento público é uma escolha que está na base da decisão sobre a destinação do orçamento do Estado, sobre a destinação das receitas tributárias. Tem-se que ter claro que estas decisões utilizam, como referência e base de análise, as estatísticas macroeconômicas geradas pelo SCN. Se, no entanto, estas estatísticas não incluem os dados separados por sexo, cor/raça nem dados sobre o valor gerado pelo trabalho não pago, pode-se concluir que as diretrizes definidas de política pública estão viesadas.

(5) Segundo dados PNAD (IBGE), no Brasil existem creches apenas para pouco mais de $30 \%$ das crianças até 3 anos. Tem-se que considerar ainda que boa parte das creches municipais não são de tempo integral. 
As estatísticas agregadas do SCN, por não incorporarem a produção gerada pelo trabalho não pago, provocam distorções nas análises macroeconômicas. A contabilidade nacional, assim estruturada, mostra apenas a evolução da capacidade produtiva mercantil da economia, desprezando ou assumindo valor zero para toda a contribuição das atividades não-remuneradas (Waring, 1988). No entanto, é importante destacar que se estas atividades não são realizadas, a produção mercantil não é possível, pelo menos não nos moldes atuais, nem seria o mesmo o estado de bem-estar social. As atividades que correspondem ao assim classificado trabalho não pago são fundamentais para as atividades mercantis gerarem a riqueza nacional, que não é fruto apenas das atividades mercantis. Existe um montante de riqueza gerado que está invisível à contabilidade nacional, mas que sem ela a vida humana seria mais precária e sua reprodução inviabilizada (Waring, 1988; Melo; Considera; Sabbato, 2007, 2016).

Um dado importante a se destacar é que a diferença dos rendimentos de mulheres e homens é sensível à idade. Segundo os dados estatísticos, no início da carreira profissional os rendimentos de mulheres e homens são mais próximos. A diferença se amplia justamente na faixa etária que corresponde à idade fértil da mulher, dos 20 aos 45 anos, quando elas relativamente perdem em rendimento e oportunidades de ocupar novos postos de trabalho (United Nations, 2016). Existe, portanto, uma relação estreita entre trabalho reprodutivo e trabalho não pago e oportunidades de emprego e de carreira profissional mais ou menos bem-sucedida. Fica evidente que as estatísticas do tempo gasto com os cuidados e o trabalho reprodutivo são fundamentais para reduzir a desigualdade e promover mais justiça entre os sexos no mercado de trabalho pago (Jain-Chandra et al., 2018). A promoção da igualdade entre os sexos é papel do Estado, através de leis e políticas públicas, e expor essa desigualdade e suas raízes é papel da disciplina de economia, no seu desenvolvimento teórico e análises econômicas. É por isso que a proposta de estruturação de um indicador para o trabalho não pago para o Brasil é atual, além de ser uma exigência da sociedade.

A mensuração dos afazeres domésticos e dos cuidados mostra que mulheres e homens exercem tarefas domésticas e cuidam de outros/as, um trabalho imprescindível para a vida humana, e que pode ser mensurado em valores monetários, ou seja, a riqueza que cria pode ser mensurada monetariamente. Para o caso brasileiro, estatísticas preliminares estimam o valor do trabalho não pago equivalendo a cerca de 11\% do PIB no período 2001-2011 (Melo; Considera; Sabbato, 2007; 2016; Melo; Thomé, 2018). Pesquisas internacionais disponíveis estimam que o trabalho não pago equivale a cerca de $13 \%$ do PIB, ou seja, aumentariam o PIB em 13\% do seu valor atual (Biyani, 2017; Velazco; Velazco, 2016).

Apesar de sua importância, como mostram as estatísticas preliminares acima, e de as mulheres estarem participando cada vez mais, desde meados do século XX, do mercado de trabalho pago, houve pouca e em alguns lugares nenhuma mudança na distribuição da carga do trabalho não pago. Não houve alteração significativa na divisão sexual do trabalho no mundo ou no Brasil, apesar de ter aumentado a tensão entre as pessoas que necessitam conciliar as tarefas dos cuidados/afazeres domésticos com o mercado de trabalho pago. E, sem dúvida, a carga de trabalho aumentou mais 
significativamente para as mulheres trabalhadoras com filhos menores, idosos ou doentes nas suas famílias, e principalmente quando separadas ${ }^{6}$ (Soares, 2008, 2016; CEPAL, 2016).

O IBGE divulgou, para 2016, os dados da nova Pesquisa Nacional por Amostra de Domicílios Contínua (PNAD-C), que investiga, além dos afazeres domésticos, informações relativas aos cuidados com as pessoas. A pesquisa introduziu mudanças no questionário base da antiga PNAD Anual e incluiu perguntas sobre atividades como: i) auxiliar alguém a se alimentar, vestir, pentear, dar remédios, banho, colocar para dormir, auxiliar nas atividades escolares, auxiliar a ler, jogar/brincar, monitorar ou fazer companhia no domicílio, transportar para a escola, para o médico, para exames, levar para o parque, para a praça, para atividades sociais, culturais, esportivas, religiosas e outras tarefas dos cuidados; e ii) perguntas sobre os afazeres domésticos: alimentação (preparar/servir), arrumar e lavar louça, limpeza do domicílio, das roupas e sapatos; pequenos reparos no domicílio, limpar e/ou manter garagem/quintal/jardim, organização do domicílio (tais como pagar contas, contratar serviços, orientar empregados, fazer compras/pesquisar preços de bens para o domicílio, cuidar dos animais domésticos e outras tarefas (IBGE, PNADC, 2017). Os resultados, divulgados no início de 2018, mostraram que, apesar de ter aumentado a percentagem de homens que responderam que realizam tarefas domésticas, o total de horas que eles gastam nestas atividades não aumentou muito ao longo dos anos de pesquisa. A diferença entre o tempo gasto pelas mulheres e pelos homens nestas tarefas também não diminuiu.

Usando os dados de 2015 como exemplo, dentre as mulheres de 16 anos ou mais ocupadas, 91\% declararam que realizavam afazeres domésticos, enquanto apenas 53\% dos homens nas mesmas condições, declararam realizar tais atividades. Estas informações são coerentes com as evidências de que os afazeres domésticos são principalmente responsabilidade das mulheres (Melo; Thomé, 2018, cap. 6).

Para 2017, os resultados da PNADC mostram que, dentre homens e mulheres acima de 14 anos de idade, $91,7 \%$ das mulheres e 76,4\% dos homens realizam afazeres domésticos. A participação nestas atividades é maior, tanto de mulheres quanto de homens, na faixa etária de 25 a 49 anos (IBGE, 2018). De forma interessante, a comparação entre as PNAD Anual e Contínua mostra aumento significativo do percentual de homens que declararam realizar afazeres domésticos, contra pequeno crescimento das declarações femininas (Gráficos 1 e 2). No entanto, este crescimento não se traduz na mesma proporção em relação ao tempo despendido nestas atividades. Os homens mantêm, ao longo do tempo, certa estabilidade em torno de 11,1 horas semanais gastas em afazeres domésticos, contra 20,9 horas das mulheres ${ }^{7}$.

(6) É mais comum que, em casos de separação dos pais, a guarda - e a carga de trabalho relativa aos cuidados - dos filhos fique com a mãe.

(7) Número médio de horas semanais dedicadas aos cuidados de pessoas e/ou afazeres domésticos dentre as pessoas de 14 anos ou mais de idade. 
Gráfico 1

Tempo dedicado a afazeres domésticos e cuidados, segundo o sexo/cor, Brasil: 2016

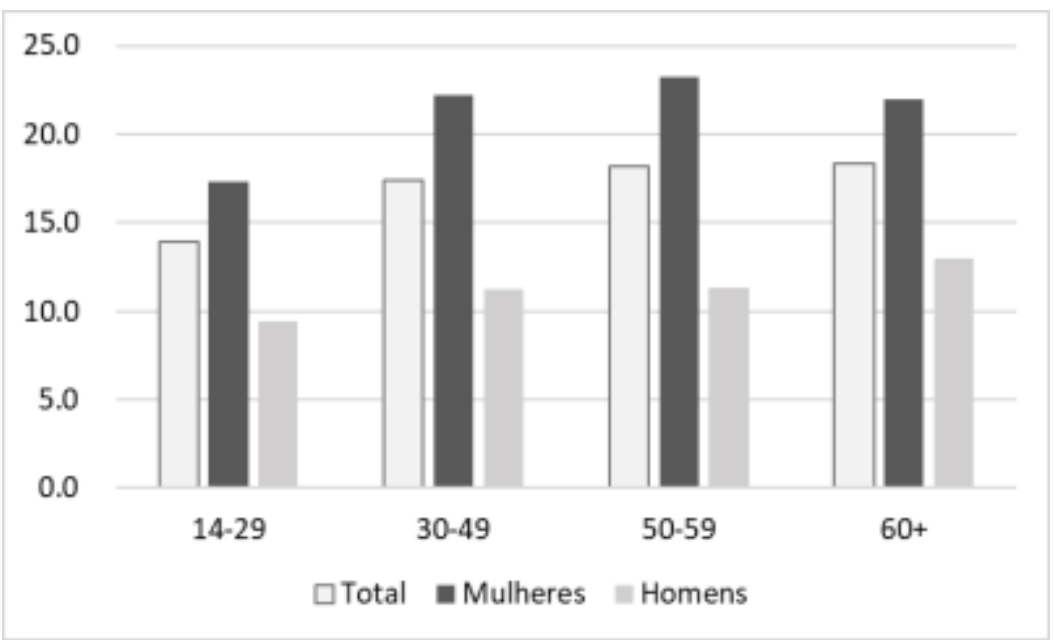

Fonte: PNAD Contínua (IBGE, 2018).

Gráfico 2

Taxa de realização de afazeres domésticos, segundo o sexo, por faixa de idade, Brasil: 2016-2017

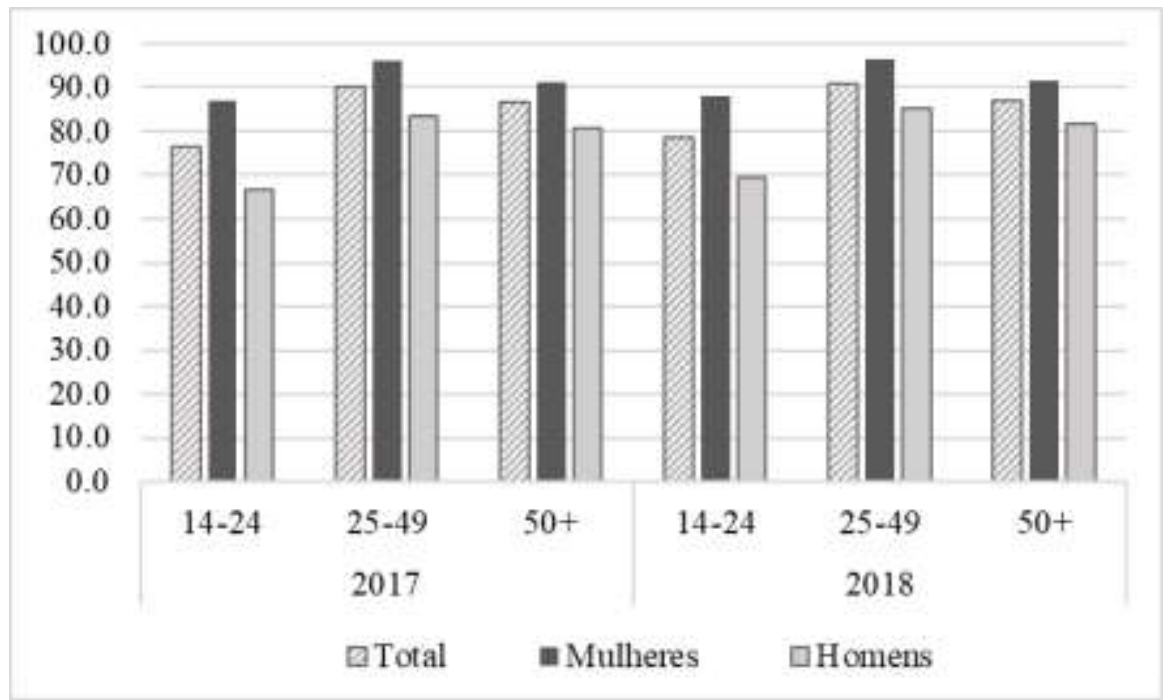

Fonte: PNAD Contínua (IBGE, 2018).

Em relação aos cuidados de pessoas, $37 \%$ das mulheres declararam que realizaram cuidados de moradores do domicílio ou de parentes não-moradores, comparado com apenas 25,6\% dos homens. Esta diferença é ainda maior na faixa etária 14-24 anos, em que 33,6\% das mulheres declararam que realizaram tarefas de cuidados contra apenas $18,5 \%$ dos homens, quase a metade da proporção de mulheres. Os resultados da pesquisa mostram também que as crianças e jovens de 0-14 anos de idade são as que recebem mais atenção e cuidados. Quando se analisam os dados segundo cor/raça, o resultado é que, entre as mulheres, as mulheres negras (pretas e pardas) dedicaram mais horas às 
tarefas de cuidados que as mulheres brancas. Essa análise para o conjunto dos homens mostra que a questão da cor/raça tem menos significância (IBGE, 2017, p. 6; IBGE, 2018, n. 38).

\section{Conta satélite do trabalho não pago: discussão sobre propostas metodológicas}

Em 1995, a Conferência das Nações Unidas para a Mulher, ocorrida em Pequim, estabeleceu um indicativo para os países criarem uma conta satélite do trabalho não pago compatível com o SCN, com o objetivo de dar visibilidade ao valor econômico gerado por esse tipo de trabalho, mostrando sua participação na geração da riqueza nacional e destacando suas conexões estruturais com o resto das atividades sociais e econômicas, o que possibilitaria a adoção de políticas públicas mais eficazes e justas para o combate às desigualdades.

A criação das contas satélites da produção das famílias (trabalho não pago) complementa as práticas em uso das Contas Nacionais e desvelam processos econômicos pouco ou mal estudados ou mesmo ignorados (Durán, 2006). Além disso, permite outros relatos e hipóteses, deixando à vista as diferentes relações entre sujeitos e atividades, abrindo caminho para uma contabilidade social mais abrangente, uma contabilidade integral.

A família é definida no SCN como "um grupo de pessoas que vive em um mesmo domicílio e compartilha despesas com alimentos e/ou habitação", podendo ser constituída de "uma ou mais pessoas" (IBGE, 2015, p. 2). O SCN calcula a contribuição das famílias relativas às suas atividades que, ou geram produção para mercado ou algum tipo de remuneração. As atividades econômicas das famílias relacionadas no SCN incluem: (i) a renda recebida na forma de salários ou outros rendimentos decorrentes de trabalho remunerado no setor privado ou público; (ii) o recebimento de renda de remuneração provenientes de atividades na qualidade de empresários, autônomos, empresas não-constituídas, agricultores (agricultura familiar), além da renda de aluguel ou de aluguel imputado (quando a casa da família é própria); e (iii) os pagamentos realizados ao empregar mão de obra remunerada para a realização de tarefas domésticas e/ou cuidados.

As famílias, além de assumirem as funções de consumidoras e empresariais, têm a função de empresas, cujos bens e serviços são produzidos e consumidos por seus próprios membros e/ou de outras famílias, para satisfazer suas necessidades básicas, garantir sua reprodução e sobrevivência. Apesar de as atividades realizadas dentro de casa não envolverem intermediação monetária, por se tratar de bens e serviços para uso final próprio não negociados em mercado, sua disponibilidade interfere diretamente no nível de bem-estar e no nível de garantia de sobrevivência dos membros da família. Como destaca Durán Heras (2006), o tempo, "o recurso que as famílias mais utilizam em suas atividades econômicas, não é pago, nem diretamente monetizado, ficando fora dos exercícios contábeis convencionais" (p. 3). As tarefas relativas ao trabalho não pago realizadas em prol das famílias definem funções de trabalho dentro da família e padrões de distribuição de tempo dos indivíduos entre o tempo destinado ao trabalho pago e ao não pago. E este planejamento do tempo é a base para se definir o trabalho não pago no interior das famílias como atividade produtiva (Inegi, 2013, p. 47).

A justificativa comum para a não inclusão dessa produção não-mercantil das famílias no SCN é que: (i) essa produção está circunscrita ao interior das famílias e tem repercussão limitada sobre o resto da economia; (ii) o valor dessa produção é difícil de ser estimado porque não se destina ao 
mercado, não se dispõe dos preços desses bens e serviços; e (iii) os valores imputados têm uma importância econômica diferente da dos valores monetários. Na verdade, segundo Durán Heras (2006), a dificuldade de se imputar valores a essas atividades é que há pouco interesse em incluí-las nas estatísticas oficiais. Isso é reflexo da forma de tratamento dessa produção pela teoria econômica, que não contabiliza a produção não-mercantil resultante do trabalho não pago realizado pelas famílias como parte da produção social total quando define os agregados macroeconômicos. E, como estas definições servem de base tanto para o cálculo dos agregados macroeconômicos pelo SCN quanto para as análises de políticas públicas e decisões das diretrizes econômicas, a não disponibilidade dos dados sobre o valor da produção do trabalho doméstico e de cuidados torna essas decisões, para dizer o mínimo, míopes $^{8}$. A estimação do valor monetário do trabalho não pago, realizado pelas e para as famílias, amigos e vizinhos, deixa claro que as transações de mercado são apenas parte dos bens e serviços disponibilizados na economia, necessários ao desenvolvimento das capacidades humanas, e que definem os padrões de vida e de bem-estar social.

Por outro lado, a mensuração do trabalho não pago não é alternativa à mensuração do PIB, mas complementar. Para se imputar valor ao trabalho não-mercantil é necessário apenas supor que existe alguma substituição entre trabalho pago e não pago, o que, segundo Folbre (2015), embora limitada, é bastante extensa. A realização do trabalho pago impõe a redução do tempo dedicado às atividades que cobrem as necessidades da família em prol do aumento do tempo dedicado à produção mercantil. Se a mulher não pode realizar os trabalhos de cuidado para a sua família, ou pelo menos não na mesma intensidade, porque se dedica ao trabalho remunerado, alguém deverá realizar suas tarefas para manter o mesmo nível de bem-estar da família. Isso implica que a mulher deva cumprir uma dupla jornada de trabalho ou que ela deverá pagar para uma substituta fazer suas antigas tarefas. De qualquer forma, o custo fica sempre com a família (é custo privado) e mais especificamente com a mulher. As estatísticas e pesquisas de uso do tempo mostram que, mesmo quando a mulher tem trabalho remunerado, ela dedica mais horas que o marido às tarefas domésticas e de cuidado.

O PIB é uma mensuração da capacidade da economia de produzir bens e serviços que cobrem necessidades (alimentação, alojamento, etc.) e geram bem-estar. Se esta medida não incorpora os valores relativos ao trabalho não pago, podemos concluir que esta é uma medida incompleta do bemestar humano, porque representa apenas a capacidade de produção (em valor monetário) dos bens e serviços produzidos e comercializados. Não se contabilizou nenhum dos demais bens e serviços, assim como a mão de obra (capacidade produtiva) correspondente, que contribuiu para a produção total, apenas porque não foram comercializados. Como o PIB é usado para ponderar a relação entre insumos e produtos (uso de recursos e produção de riqueza), ao ignorar a contribuição importante de alguns insumos, como o trabalho não pago, sua medida exagera a eficiência e a importância do produto resultante da produção mercantil.

Existem duas metodologias para a estimação do valor da produção gerada pelo trabalho não pago. Uma delas utiliza o valor de mercado do salário-hora para a atividade correspondente ao trabalho não pago, multiplicado pelo número de horas dedicadas ao trabalho no interior das famílias. Uma segunda forma de estimação utiliza o custo de oportunidade. Nesse caso, utiliza como referência de valor o salário-hora recebido nesta atividade no mercado multiplicado pelas horas que dedica ao

(8) Sobre invisibilidade do trabalho das mulheres e teoria econômica, ver também Melo e Serrano (1997). 
trabalho não pago. Esta é uma medida aproximada do quanto a pessoa estaria disposta a pagar a seu substituto no trabalho não pago. Esta forma de medição, no entanto, não é compatível com as contas nacionais porque o valor corresponde a uma renda desejada ou suposta e que pode não corresponder ao salário de mercado que a pessoa conseguiria. Uma terceira forma estima o valor de mercado de produto similar para mensurar o trabalho não pago. Utilizando o preço de mercado de uma refeição, p. ex., e o custo de se produzir esta mesma refeição em casa (custo dos ingredientes), a diferença entre os dois equivale ao valor do trabalho para a realização dessa atividade no interior das famílias 9 .

As várias pesquisas realizadas em diversos países mostram que as mulheres são as principais responsáveis pelo trabalho não pago, estando sujeitas a um número maior de horas de trabalho (pago e não pago) do que os homens (CEPAL, 2019; Global Gender Gap Report 2017, 2017; Aguirre; Ferrari, 2014; Durán Heras, 2012). Deve-se ter em mente que o trabalho não pago não pode ser aleatório, realizado ou não segundo o humor ou desejo dos membros participantes da família. Na verdade, é um trabalho rotineiro e que deve ser meticulosamente estruturado. É um trabalho vital para satisfazer as necessidades diárias e garantir o bem-estar dos membros das famílias, tendo especial relevância para as pessoas que necessitam de cuidados, como as crianças, os idosos e as pessoas que sofrem de alguma doença ou incapacidade temporária ou permanente. As atividades do trabalho doméstico e de cuidados não são meramente secundárias dentro do esquema de produção da sociedade. São atividades fundamentais, que têm que ser realizadas por alguém e que demandam tempo de quem as realiza.

Claramente, os cuidados despendidos por membros da família (em sua grande maioria pelas mulheres) substituem alguns gastos sociais e investimentos públicos destinados à assistência social. Nesse caso, os membros das famílias que realizam o trabalho não pago substituem as creches e escolas de tempo integral, assim como os centros de atenção e assistência a idosos e enfermos. Mas as famílias cumprem estas tarefas de forma desigual. Nas famílias com maior renda, estes serviços são realizados por terceiros, ou por mão de obra contratada (empregada/o doméstica/o) ou pela compra desses serviços (contratação de serviços de creches e escolas). Para as famílias de menor renda, sem poder aquisitivo para contratação de terceiros ou compra de serviços de creche e escola particulares, há uma distribuição de tarefas entre os membros da família e, geralmente cabe à mulher as tarefas domésticas e de cuidados. Alternativamente, principalmente em famílias monoparentais em que a mulher é a chefe da família, as mulheres não podem deixar de trabalhar e normalmente cumprem dupla jornada de trabalho. Esta situação é ainda mais precária quando a mulher tem filhos. A carga de trabalho é maior e a possibilidade de ter um trabalho de tempo integral com boa remuneração diminui muito.

É nesse sentido que tanto as decisões de políticas públicas que não levam em conta as desigualdades de gênero quanto os cortes de gastos públicos são injustos, pois impactam mais fortemente as famílias de menor renda e com menor capacidade de pagar a terceiros pelos serviços de cuidados. E, como são as mulheres que majoritariamente prestam os serviços de cuidado ou trabalho não pago no interior das famílias, os cortes de gastos públicos impactam também mais fortemente as mulheres e sua capacidade de se dedicar à profissão e competir em igualdade de

(9) Mesmo assim, podem existir insumos e produtos não mensuráveis, que vão além da refeição em si, como o maior valor nutricional da refeição caseira e a possibilidade de maior interação social dos membros da família, que pode gerar um nível de bem-estar maior que fazer uma refeição num restaurante. (Folbre, 2015). 
condições com os homens no mercado de trabalho. Este fato é ainda mais relevante nos países não centrais, onde as mulheres gastam mais tempo nas tarefas de cuidados. Nessas regiões, os investimentos em infraestrutura (eletricidade, gás, água encanada, esgotamento sanitário, etc.) representam grandes ganhos de produtividade do trabalho doméstico e de cuidados, além da melhora na saúde de crianças e idosos, com a consequente redução do tempo dispendido nestas atividades.

Mais recentemente, o déficit de cuidados nos países mais ricos, segundo Werner et al. (2007), fruto do aumento da participação feminina no mercado de trabalho pago e da maior idade média de vida de sua população, tem sido coberto com o emprego de mulheres imigrantes, geralmente provenientes de países mais pobres. Em muitos casos, as mulheres migram sem poder levar os filhos, criando maior déficit de cuidados nos países mais pobres, aumentando a desigualdade em relação à qualidade de vida entre esses dois blocos de países.

Para tornar visível o trabalho não pago através da exposição do valor econômico que gera em bens e serviços, as pesquisas de uso do tempo são indispensáveis. Essas pesquisas devem ser estruturadas cuidadosamente e devem cobrir todas as atividades específicas de cuidados de pessoas e as relativas à manutenção da casa. A inclusão desses dados no SCN é feita através da criação de uma conta satélite específica. O resultado é um valor de PIB que incorpora também o valor do trabalho não pago. (Aguiar, 2010; Bandeira, 2010; Fontoura et al., 2010).

Segundo Folbre (2015), a crítica de que a inclusão do valor do trabalho não pago nas Contas Nacionais através de conta satélite causaria distorções é infundada. Na verdade, as Contas Nacionais já criam distorções importantes na forma como estão estruturadas, ao imputarem valor nulo ao trabalho não pago. Atualmente, o valor gerado pela amamentação materna em termos de benefícios médicos para o bebê, p. ex., não está incluído no valor do PIB. Porém, estão incluídos os gastos com os alimentos industrializados, de pior qualidade, usados em substituição ao aleitamento materno. Por outro lado, o SCN já incorpora, em vários países, valores imputados relativos a serviços como as transações ilegais de drogas e a prostituição, mesmo sabendo-se que os dados são precários. Também são exemplo a incorporação de novos procedimentos para valorar a contribuição do setor financeiro para a economia a partir do nível da taxa de juros. Nesse caso, supõe-se que maiores juros remuneram melhores e maiores serviços gerados, ignorando o fato de que juros maiores implicam também maiores riscos de inadimplência e possibilidade de crise econômica. Como afirma Folbre, "comparativamente a essas revisões recentes, a mensuração do trabalho não-mercantil baseia-se em fundamentos metodológicos especialmente sólidos" (2015, p. 8).

\section{Estimação do trabalho não pago para o Brasil: uma proposta embrionária}

As pesquisas de uso do tempo são o principal instrumento para a mensuração do trabalho não pago realizado no interior das famílias, permitindo a estimação do valor dessa produção e os custos de reposição dessas atividades pelo mercado. Estas pesquisas utilizam perguntas para estimar o tempo dedicado a atividades específicas, como preparação de alimentos, limpeza e manutenção da residência e cuidados com as crianças (Quadro 1).

A metodologia destas pesquisas ainda pode ser melhorada, como destaca Folbre (2015). Elas podem estar subestimando a geração de riqueza pelo trabalho não pago. Isto porque, primeiro, não conseguem captar o tempo gasto na supervisão dos cuidados, o chamado plantão de responsabilidade. 
Segundo, porque não são pesquisados todos os membros da família, mas apenas um adulto (maior de 14 anos), escolhido aleatoriamente. O resultado, nesse caso, não permite a medição direta do valor do trabalho não pago por tipos de família, que seria uma informação importante sobre o padrão de vida das famílias. E, terceiro, porque poucas pesquisas sobre uso do tempo incluem perguntas sobre as características dos gastos de consumo, sobre os ativos domésticos disponíveis para auxiliar as tarefas, ou sobre as condições de saúde de seus membros. Esses aspectos têm relevância porque a desigualdade pode ter aumentado mais do que os dados mostram. $\mathrm{O}$ aumento da participação da mulher no mercado de trabalho pode ter levado à perda de qualidade dos cuidados dispensados às crianças e à família, principalmente para as classes de menor renda, que não podem pagar por serviços substitutos adequados (Aguiar, 2010).

Quadro 1

Atividades das famílias incluídas e excluídas do Sistema de Contas Nacionais

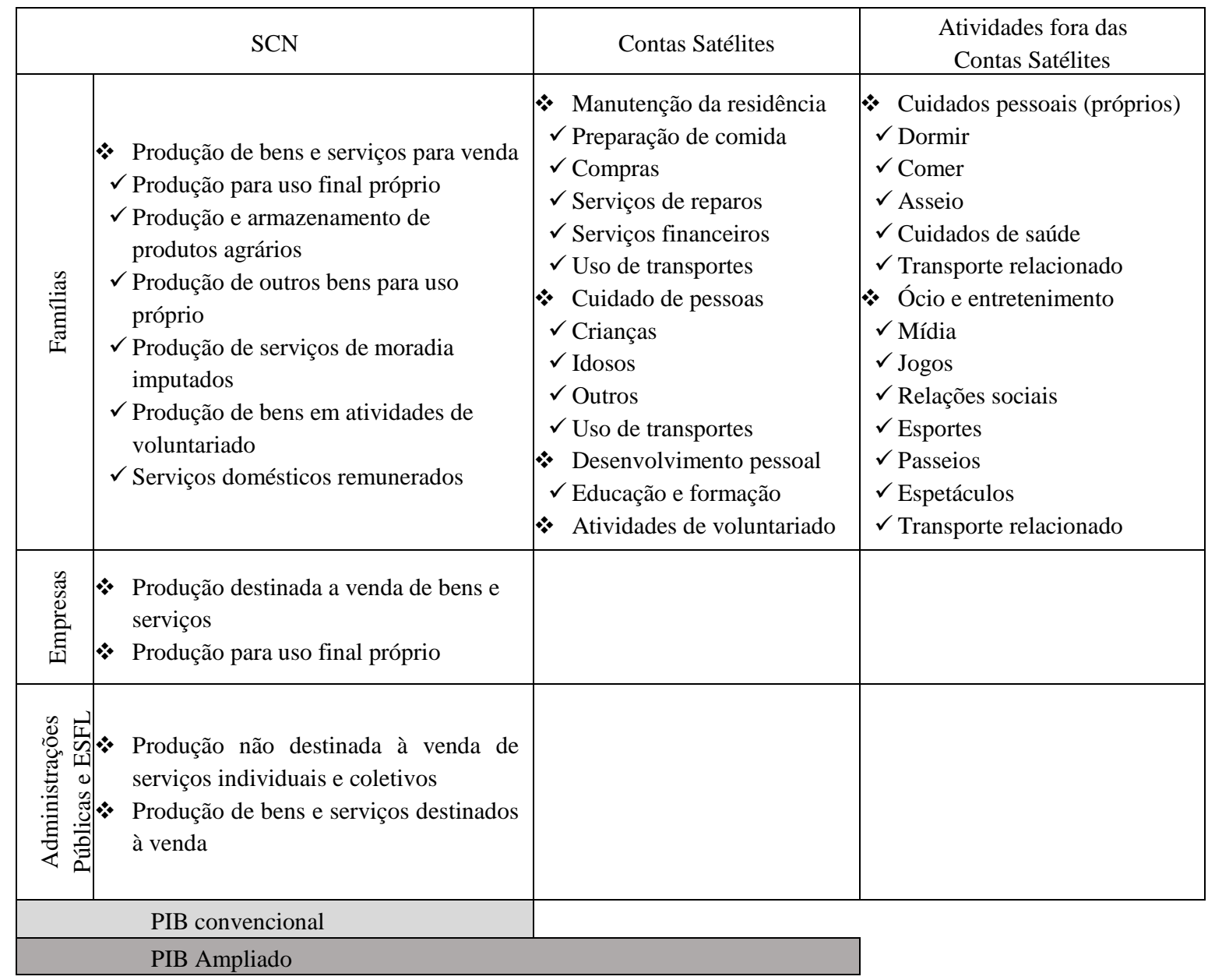

Fonte: Ver Durán Heras (2006, p. 21). 
Pode-se definir uma atividade como trabalho (versus lazer) se uma pessoa pode ser paga para realizá-la (Werner et al., 2007) e pode-se considerá-la produtiva se proporcionar um produto ou serviço que pode ser trocado/vendido no mercado. O critério chave para definir uma atividade produtiva é quanto custaria substituir a dedicação de uma pessoa por outra que faz o mesmo trabalho cobrando por isso. Por outro lado, a produção doméstica inclui um conjunto de atividades nãoremuneradas realizadas em prol da família ou pessoas externas que podem ser substituídas por produtos ou serviços adquiridos no mercado, como o alojamento, a alimentação, o vestuário e os cuidados. Mas, apesar de essas atividades serem trabalho e serem produtivas, elas são social, política e economicamente desvalorizadas. Convencionalmente, a teoria econômica definiu trabalho apenas quando a atividade é remunerada e os bens e serviços produzidos são comercializados no mercado por um preço monetário. A proposta dos movimentos sociais e feministas é que seja incorporada à teoria econômica a classificação mais ampla de trabalho, que incorpora outras categorias de geração de riqueza que não apenas a de trabalho mercantil ${ }^{10}$. E, como resultado dos movimentos sociais, em 1993, a Comissão de Estatísticas das Nações Unidas abriu a possibilidade de incorporação da produção doméstica nas Contas Nacionais, ampliando os limites da produção agregada considerada. O desenvolvimento metodológico culminou na publicação, em 2003, do Household Production and Consumption Proposal for a Methodology of Household Satellite Accounts (European Comission).

Cada país define, dentre as atividades desempenhadas no interior das famílias, quais as principais a serem consideradas na pesquisa de uso do tempo, baseadas nas tarefas fundamentais ou vitais para a vida e manutenção das famílias. Tradicionalmente, as seis atividades principais definidas são a provisão de: alojamento, refeições e lanches, vestuário e cuidados com as roupas, transportes de crianças e/ou idosos ou para ir às compras, gerenciamento e administração da casa, cuidados dispensados a crianças e idosos e trabalhos voluntários (Quadro 2). A estimação do produto econômico gerado por essas atividades depende diretamente da escolha dos ponderadores, como total de horas dedicadas a essas atividades e o preço por hora por atividade. Por isso há necessidade de pesquisas específicas e bem delineadas.

A pesquisa deve ser estruturada de forma a obter a informação estatística sobre o tempo dispendido pelos membros da família e quais as atividades diárias realizadas que podem ser classificadas como trabalho não pago. Os dados são coletados por meio de entrevistas diretas com os membros da família, cobrindo atividades realizadas relacionadas à promoção de alimento, cuidado, segurança e bem-estar dos membros da família, bem como das atividades classificadas como trabalho voluntário, dispensadas a parentes, vizinhos ou organismos comunitários. As estatísticas resultantes dessas pesquisas são importantes porque mostram as deficiências de serviços públicos, tanto em termos de quantidade quanto de qualidade, e devem servir de base para a definição de estratégias de políticas públicas que visem reduzir as desigualdades sociais e de gênero, proporcionando melhoria da qualidade de vida da população. Esses objetivos podem ser alcançados com definições de políticas públicas que aumentem a disponibilidade de serviços públicos em quantidade e de qualidade para cobrir as demandas, como: serviços de transporte eficientes e de qualidade, que reduzam o tempo e o custo de deslocamento entre trabalho e casa e lazer, serviços de cuidado de qualidade e a preços acessíveis, a crianças, idosos e necessitados de cuidados especiais, como creches e centros de atenção, disponibilidade de vagas em escolas públicas de qualidade e próximas às residências, escolas públicas

(10) As Nações Unidas incluíram também o trabalho voluntário, sem remuneração, realizado para membros fora da família ou entidades sem fins lucrativos, na definição de trabalho não pago. Entidades sem fins lucrativos são organizações privadas, sem finalidade lucrativa, que não distribuem excedente aos controladores ou dirigentes, são autogeridas e garantem liberdade de adesão e contribuição (European Comission, 2003). 
com horário integral para o grupo de crianças de idades menores, acesso a água e esgoto tratados e coleta de lixo adequada, áreas de lazer seguras, próximas às residências e em número suficiente para cobrir demanda da população do entorno, são exemplos dessas políticas. Essas políticas públicas são fundamentais para reduzir desigualdade porque elas permitem que as pessoas de menor renda, e principalmente as mulheres de menor renda, tenham condições de competir no mercado de trabalho em melhores condições. Sem esses serviços, nas famílias de baixa renda geralmente as mulheres se tornam economicamente dependentes porque não conseguem participar do mercado de trabalho em condições plenas, forçando-as a buscarem trabalhos de meio expediente ou com horários mais flexíveis o que no geral implica piores condições de trabalho e menor renda. As famílias monoparentais chefiadas por mulheres e com filhos têm maior probabilidade de serem pobres, e isso piora ainda mais para as mulheres negras.

Quadro 2

Categorias a serem consideradas nas pesquisas sobre trabalho não pago

\begin{tabular}{|c|c|}
\hline Atividades de trabalho não-remunerado & Valoração - Modelos alternativos \\
\hline * Trabalho doméstico (na residência da família, de & * $\quad$ Modelo de saída ou output (produto) \\
\hline vizinhos ou parentes) & $\checkmark \quad$ Estima volume e valor do produto ou serviço \\
\hline$\checkmark \quad$ Preparo de alimentos/refeições & pelo preço do bem/serviço correspondente adquirido \\
\hline$\checkmark \quad$ Lavar pratos e vasilhas & no mercado, p. ex., preço de uma refeição semelhante \\
\hline Lavar e passar roupas e limpar sapatos & no restaurante \\
\hline$\checkmark \quad$ Limpeza, manutenção e pequenos reparos de & * Modelo de entrada ou input \\
\hline bens duráveis ou não & $\checkmark \quad$ Pesquisas de uso do tempo: Estima o número de \\
\hline$\checkmark$ Compras ou obtenção de serviços e & horas dispensadas na atividade não-remunerada vezes \\
\hline administração & o preço da hora de trabalho remunerado em atividade \\
\hline$\checkmark \quad$ Pagamento de contas e outras transações & semelhante \\
\hline Manutenção da casa & $\checkmark \quad$ Valor do trabalho: \\
\hline$\checkmark \quad$ Limpeza, embelezamento, manutenção e & $\checkmark \quad$ Custo de oportunidade: tempo dispendido na \\
\hline pequenos reparos & atividade não-remunerada vezes o preço-horada \\
\hline$\checkmark \quad$ Atividades de trato de jardim e horta & atividade exercida no mercado de trabalho \\
\hline Gerenciamento da casa (inclusive financeiro) & remunerado \\
\hline * Cuidados dispensados a pessoas (crianças, idosos & $\checkmark \quad$ Custo de substituição: quanto se está disposto a \\
\hline ou enfermos) & pagar para alguém fazer a atividade \\
\hline$\checkmark \quad$ Cuidado, formação e educação de crianças & \\
\hline Cuidados de saúde & Outros indicadores sociais a serem considerados: \\
\hline$\checkmark \quad$ Cuidados dispensados a outros membros da & $\checkmark \quad$ Sexo \\
\hline família & $\checkmark \quad$ Idade \\
\hline Outros cuidados & Raça \\
\hline Viagens relacionadas a esses cuidados & Local de nascimento \\
\hline Atividades civis ou em organizações & Estado civil \\
\hline$\checkmark \quad$ Trabalho voluntário em eventos sociais ou & Presença de crianças ou idosos na família \\
\hline órgãos da comunidade & \\
\hline$\checkmark$ Trabalho voluntário formal numa organização, & \\
\hline como captação de recursos & \\
\hline$\checkmark \quad$ Trabalho voluntario informal a outras residências & \\
\hline ou parentes & \\
\hline
\end{tabular}

Fonte: Gómez Luna (2010); Werner et al. (2007); CEPAL (2016). 
A estruturação da pesquisa e a definição das perguntas, segundo Gee (2015), são fundamentais para que o resultado seja confiável e compatível, tanto para serem comparáveis no tempo e quanto comparáveis com as informações de outros países. Algumas observações pautadas nas experiências mostram que, primeiro, o formato da pesquisa não deveria eliminar a possibilidade de se fazer mais de uma atividade ao mesmo tempo, como fazer comida e tomar conta de criança, para não haver subestimação das horas dedicadas ao trabalho não pago, o que levaria a uma subestimação do valor dos bens e serviços produzidos. Segundo, estudos mostram que quando a pesquisa dispõe da lista de atividades a serem consideradas, o número de respostas é maior do que quando a pessoa entrevistada tem que escrever cada atividade realizada (Quadro 3). Essa vantagem deve, no entanto, ser ponderada porque, apesar de a lista facilitar a resposta, ela também simplifica as descrições e torna as categorias mais subjetivas, podendo causar dúvidas à pessoa entrevistada. E, terceiro, a valoração dessas atividades é feito atribuindo-se um preço por hora de trabalho para as diferentes atividades, segundo informações de estatísticas de emprego. Este valor, no entanto, referese à renda por hora e não ao pagamento efetivo pela atividade porque não inclui outros custos relativos à contratação de mão de obra ou serviço no mercado, como previdência, seguridade, etc. (Gómez Luna, 2010). Essas limitações, no entanto, não invalidam as estimativas como fonte empírica de análise, definição e avaliação de políticas públicas baseadas em gênero.

Como estas estatísticas servirão para análises macroeconômicas, seu tratamento deve ser similar ao dado ao levantamento de informações relativas às atividades incorporadas no SCN. Sendo a valoração da atividade não-remunerada feita a partir do preço por hora de trabalho pago para atividade semelhante e, como os dados sobre preço por hora de trabalho disponíveis não são tão detalhados quanto as atividades pesquisadas, deve-se usar um preço por hora de trabalho remunerado correspondente a um conjunto de atividades do trabalho não pago. Multiplicando-se o preço por hora de trabalho pelo número de horas semanais dedicadas às atividades remuneradas, obtém-se o valor do trabalho não pago. $\mathrm{O}$ valor da produção de cada atividade resulta numa conta satélite e a soma corresponde ao produto agregado ou PIB do trabalho não pago. O valor do trabalho não pago é calculado como:

$$
\operatorname{VTNR}_{t}=\mathrm{CMeT}_{t} * \frac{\mathrm{HMe}}{\mathrm{dia}} * 365 * \mathrm{Pop}_{15+}
$$

onde, VTNR é o trabalho não pago em valor corrente; $C M e T$ é o custo médio da hora de trabalho (inclusive impostos); HMe é a média de horas trabalhadas; vezes 365 dias no ano; e Pop a população com 15 anos ou mais, calculados para o ano $t$. E o valor do serviço dos bens de capital é:

$$
V S B D_{t}=I P B D_{t} * E L B D_{t} *\left(T R_{t}+D_{t}\right)
$$

sendo, VSBD o valor do serviço dos bens de consumo duráveis; IPBD o índice de preço para bens de consumo duráveis; $E L B D$ o estoque líquido de bens de consumo duráveis; e $T R$ e $D$ as taxas de retorno e de depreciação, respectivamente. O valor da produção não-mercantil das famílias, PIBFam, é a soma desses dois valores:

$$
\text { PIBFam }_{t}=\operatorname{VTNR}_{t}+V S B D_{t}
$$

Esta forma de cálculo permite que se tenha um quadro bem definido sobre a representatividade do trabalho não pago em termos de geração de riqueza para a sociedade em relação ao produto agregado total (PIB). Afinal, estas estimativas se coadunam bem ao objetivo do SCN, que é medir toda a produção de bens e serviços disponibilizados na economia e que corresponde à capacidade da economia de gerar riqueza e criar condições de bem-estar, mesmo quando os bens e serviços não tenham sido comercializados e são para consumo próprio da família ou da comunidade. 
Mesmo nesse caso, essas atividades geraram bens e serviços, supriram necessidades e precisam continuar a serem produzidas. Por isso são classificadas como trabalho e, como tal, produzem riqueza para a sociedade. Devem, portanto, fazer parte das estatísticas macroeconômicas oficiais e das análises sobre as diretrizes e objetivos das políticas públicas.

Além disso, a presença ou não de bens de capital deve ser considerada na pesquisa, como ir ao mercado de carro, bicicleta ou outro meio de transporte ou a pé, lavar a roupa à mão ou a máquina, varrer a casa ou usar aspirador de pó. A metodologia proposta é imputar um valor ao serviço proporcionado pelo bem de capital, correspondente ao custo do aluguel do bem ou do serviço correspondente. Isso permite diferenciar as famílias com mais acesso a bens de capital para ajudar nas tarefas domésticas e de cuidado.

A estimação e incorporação do valor do trabalho não pago às demais estimativas de produção das Contas Nacionais através das contas satélites não traz nenhum prejuízo ou distorção às medições do PIB e, por outro lado, garante a correta avaliação da capacidade da economia de gerar riqueza. Não se pode desconsiderar o fato de que as pessoas que estão trabalhando no mercado dependem de algum tipo de suporte para se ausentar da sua casa durante o seu horário de trabalho. Esse trabalho silencioso, que na sua grande maioria é realizado pelas mulheres, é essencial para o funcionamento da economia.

Quadro 3

Estrutura da Pesquisa: lista de atividades

\begin{tabular}{|c|c|}
\hline Prestação de serviços domésticos não-remunerados à família & Tempo \\
\hline $\begin{array}{ll}\checkmark & \text { Cozinhar e preparar alimentos } \\
\checkmark & \text { Servir a refeição, por e limpar a mesa } \\
\checkmark & \text { Lavar, enxugar e guardar louças } \\
\checkmark & \text { Limpar ou lavar eletrodomésticos } \\
\checkmark & \text { Limpar ou lavar banheiro } \\
\checkmark & \text { Lavar roupa dos membros da família } \\
\checkmark & \text { Passar roupa dos membros da família } \\
\checkmark & \text { Dobrar e guardar a roupa da família } \\
\checkmark & \text { Limpar ou escovar os sapatos } \\
\checkmark & \text { Arrumar cama ou quarto de dormir } \\
\checkmark & \text { Limpeza geral da casa } \\
\checkmark & \text { Tirar o lixo } \\
\checkmark & \text { Lavar o carro ou outro meio de transporte da família } \\
\checkmark & \text { Reparar o carro ou outro meio de transporte } \\
\checkmark & \text { Pequenos reparos elétricos, encanamento e canalizações } \\
\checkmark & \text { Pequenos reparos em eletrodomésticos ou móveis } \\
\checkmark & \text { Fazer móveis, ornamentos, ou artesanatos para a casa } \\
\checkmark & \text { Fazer a contabilidade da família } \\
\checkmark & \text { Fazer o pagamento dos serviços } \\
\checkmark & \text { Pagar cartão de crédito, mensalidades e dívidas da } \\
\text { família, fazer depósitos } \\
\checkmark & \text { Supervisionar reparos ou levar carro, eletrodoméstico, } \\
\text { móveis etc. para conserto } \\
\checkmark & \text { Cuidar de animais de estimação } \\
\checkmark & \text { Fazer as compras diárias de supermercado } \\
\checkmark & \text { Comprar roupa e sapatos para membros da família } \\
\checkmark & \text { Comprar eletrodomésticos e móveis para a família } \\
\checkmark & \text { Tomar conta de negócio próprio ou da família } \\
\checkmark & \text { Levar roupas para consertar ou limpar ou pegar }\end{array}$ & $\begin{array}{c}\text { Informação sobre o número de horas } \\
\text { semanais gastas em cada atividade } \\
\text { h/semana }\end{array}$ \\
\hline
\end{tabular}

Continua... 
Quadro 3 - Continuação

\begin{tabular}{|c|c|}
\hline \multicolumn{2}{|c|}{ Serviços domésticos de cuidados não-remunerados para membros da família } \\
\hline $\begin{array}{l}\checkmark \quad \text { Ajudar membro da família com dificuldades físicas ou } \\
\text { mentais } \\
\checkmark \quad \text { Banhar ou vestir membro da família com dificuldades } \\
\text { físicas ou mentais } \\
\checkmark \quad \text { Levar ao banheiro ou trocar fraldas a membro da família } \\
\text { com dificuldades físicas ou mentais } \\
\checkmark \quad \text { Cuidar de membro da família temporariamente doente } \\
\checkmark \quad \text { Acompanhar membro da família a qualquer lugar } \\
\checkmark \quad \text { Ajudar a criança a se alimentar } \\
\checkmark \quad \text { Banhar e vestir uma criança } \\
\checkmark \quad \text { Brincar ou conversar com uma criança } \\
\checkmark \quad \text { Ajudar com terapia especial a uma criança } \\
\checkmark \quad \text { Ajudar com os deveres de casa ou estar disponível para } \\
\checkmark \quad \text { Levar membro da família com dificuldades físicas ou } \\
\text { mentais para visita médica, terapia ou outra atividade ou } \\
\text { negócio } \\
\checkmark \quad \text { Levar membro da família da família a algum lugar ou } \\
\text { pegar } \\
\checkmark \quad \text { Levar comida para local de trabalho ou escola para um } \\
\text { membro da família } \\
\checkmark \quad \text { Ajudar com terapia especial para um membro da família } \\
\text { com dificuldades físicas ou mentais }\end{array}$ & $\mathrm{h} /$ semana \\
\hline \multicolumn{2}{|c|}{ Prestação de serviços não-remunerados à comunidade e outras famílias } \\
\hline 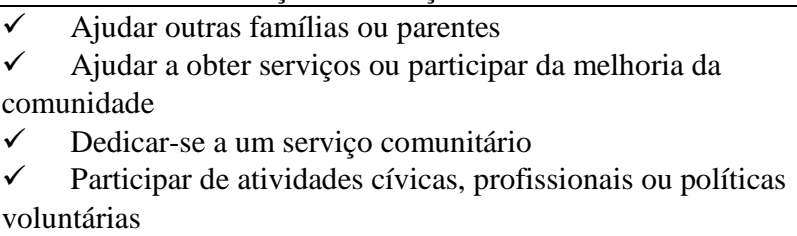 & $\mathrm{h} /$ semana \\
\hline
\end{tabular}

Fonte: Gómez Luna (2010, p. 51); Werner et al. (2007); CEPAL (2016).

O que se tem aprendido ao longo do tempo é que este trabalho só pode ser substituído, nunca eliminado. E mais, quando substituído por serviço privado doméstico pago, cria distorções porque só favorece quem tem renda suficiente para pagar por tais serviços. A forma socialmente justa de se promover a substituição do trabalho não pago é através da oferta de serviços públicos substitutos em quantidade suficiente para a população, principalmente a que tem menor renda, e serviços de qualidade, como creches, centros auxiliares de recuperação/apoio para doentes e/ou idosos, acesso a água e esgoto tratados, coleta adequada de lixo, etc. E só vamos conhecer a verdadeira dimensão da necessidade desses serviços públicos quando o trabalho não pago for adequadamente quantificado e deixar de ser uma estatística invisível à sociedade e às políticas públicas.

\section{Considerações finais}

Este estudo propõe a discussão de um indicador social do trabalho não pago para o Brasil, a ser incorporado ao Sistema de Contas Nacionais (SCN), através da criação de uma conta satélite, cumprindo assim as recomendações da Organização das Nações Unidas listada nos Objetivos do Milênio 2030 (Objetivo 5, Item 5). Esta é uma proposta metodológica defendida pela economia feminista, com intenção de dar visibilidade às atividades dirigidas ao bem-estar das pessoas e 
realizadas majoritariamente pelas mulheres. Apesar de ainda não haver no Brasil uma pesquisa nacional sistemática de uso do tempo, para servir de base à criação de uma Conta Satélite do trabalho não pago, é possível fazer estimativas sobre seu valor a partir dos dados de algumas pesquisas, como a PNAD/IBGE (Melo; Considera; Sabatto, 2007, 2016; Morandi; Melo; Dweck, 2018). Os resultados já obtidos, mesmo que precários, destacam a importância econômica do trabalho não pago. É preciso sensibilizar a sociedade para a questão da invisibilidade do trabalho não pago e suas consequências sobre a desigualdade.

A divisão sexual do trabalho, consagrada pela industrialização, associou a atividade mercantil ao sexo masculino e ao feminino a produção doméstica, sem valor de mercado. Na realidade, isso significou a ocultação de uma parte significante do trabalho feminino, denunciado pelas economistas feministas internacionais nas últimas décadas (Durán Heras, 2006; Picchio, 1999; Carrasco, 1999, 2006, 2012; Folbre, 2015; Waring, 1988, Friedan, 1971). Na esteira deste debate, ainda que de forma mais tímida, essa discussão também foi feita no Brasil. E este artigo expressa a continuidade desta linha de pesquisa e das tentativas de políticas públicas ensaiadas pelo governo brasileiro no período 2004-2016. Com o avanço da pauta feminista, através de políticas públicas contra a desigualdade e discriminação por gênero e raça/etnia da última década, ampliou-se o debate sobre estes temas, agora com enfoque macroeconômico explicitado, e este artigo se junta a esse momento de ascenso da economia feminista no debate econômico.

A proposta de criação deste indicador socioeconômico de gênero para o Brasil permite desvendar a contribuição das mulheres através do que está/estava oculto pela contabilidade social. O trabalho das mulheres no interior das famílias, pelo fato de serem atividades não permeadas por trocas monetárias, num recorte androcêntrico, são vistas como não trabalho, desde a origem do pensamento econômico. Assim, o questionamento dos fundamentos do discurso economicista tem, na criação de uma conta satélite para trabalho não pago, um marco para que políticas públicas sejam desenvolvidas e implementadas para equacionar as demandas das famílias por creches, escola em tempo integral, equidade salarial entre homens e mulheres e pela redução da dependência econômica das mulheres na sociedade.

A criação da conta satélite do trabalho não pago complementa as práticas em uso das Contas Nacionais e desvela processos econômicos pouco ou mal estudados ou mesmo ignorados. Além disso, permite outros relatos e hipóteses, deixando à vista as diferentes relações entre sujeitos e atividades, abrindo caminho para uma contabilidade social mais abrangente e integral. Na verdade, como vimos neste trabalho, a dificuldade de se imputar valores a essas atividades é que há pouco interesse em incluí-las nas estatísticas oficiais. Isso é reflexo de como a teoria econômica define produção e trabalho, tornando invisível o trabalho não pago por não contabilizar como produto os bens e serviços gerados pelo trabalho não pago realizado pelas famílias, nem os considerar parte da produção social total quando define os agregados macroeconômicos.

Compreendemos que as estatísticas do valor do trabalho não pago são um indicador macroeconômico que complementa a medição do PIB, no sentido de permitir mensurar e representar melhor a produção agregada da economia assim como ter uma melhor visualização das fontes de geração de riqueza na economia, ao mostrar o valor criado pelo trabalho não pago na forma de bens e serviços que permitem melhorar o nível de bem-estar social. Além disso, estas estatísticas permitem 
que se delineiem desigualdades, inclusive a de gênero, ao expor a verdadeira contribuição das pessoas que "não trabalham" e apenas fazem o trabalho doméstico e de cuidados, um tipo de trabalho considerado menor, apesar de essencial. Com isso, é possível desenhar políticas públicas mais adequadas e eficientes para promover, senão a extinção, pelo menos a redução das desigualdades, além de adequar o Brasil aos Objetivos do Milênio propostos pela ONU.

\section{Referências bibliográficas}

AGUIAR, Neuma (Coord.). Mulheres na força de trabalho na América Latina: análises qualitativas. Petrópolis, RJ: Vozes, 1984.

AGUIAR, Neuma. Metodologias para o levantamento do uso do tempo na vida cotidiana no Brasil. Revista Econômica, v. 12, n. 1, p. 64-82, 2010.

AGUIRRE, Rosario; FERRARI, Fernanda. Las encuestas sobre uso del tempo y trabajo no remunerado en América Latina y Caribe: caminos recorridos y desafíos hacia el futuro. Santiago de Chile: Naciones Unidas, Feb. 2014. (Serie Asuntos de Género, n. 12).

BEAUVOIR, Simone. O segundo sexo. 2. ed. Rio de Janeiro: Nova Fronteira, 1980, 2v. $1^{\mathrm{a}}$. ed. francesa 1949.

BANDEIRA, Lourdes. Importância e motivações do Estado brasileiro para pesquisas de uso do tempo no campo de gênero. Revista Econômica, v. 12, n. 1, p. 47-63, 2010.

BIYANI, Neeti. Think taxis gender neutral? Think again: why countries need to put women at the heart of their tax regimes. International Politics and Society, Oct. 5, 2017. Available at: http://www.ips-jopurnal.eu/about/human-rights/article/show/lets-not-lose-our-thread-2155/.

CARRASCO, Cristina. Estatísticas suspeitas: proposta de novos indicadores com base na experiência das mulheres. São Paulo: SOF Sempreviva, Organização Feminista, 2012.

CARRASCO, Cristina. Hacia una nueva metodología para el estudio del tiempo y del trabajo. In: METODOLOGÍAS para la medición del uso del tiempo con perspectiva de género. Buenos Aires: Consejo Nacional de la Mujer, Embajada de España en Argentina, Agencia Española de Cooperación Internacional, Oficina Técnica de Cooperación, 2006.

CARRASCO, Cristina (Org.). Mujeres y economía: nuevas perspectivas para viejos y nuevos problemas. Barcelona: Icaria, 1999.

CEBOTAREV, E. A. A organização do tempo de atividades domésticas não-domésticas de mulheres camponesas na América Latina. In: AGUIAR, Neuma (Coord.). Mulheres na força de trabalho na América Latina: análises qualitativas. Petrópolis, RJ: Vozes, 1984.

COMISIÓN ECONÓMICA PARA AMÉRICA LATINA Y EL CARIBE - CEPAL. La distribución del tempo: una dimensión clave em el análisis de la desigualdad. In: PANORAMA Social de la América Latina, 2016. Cap. IV.

DEDECCA, C. S. Uso do tempo e gênero. Uma dimensão da desigualdade socioeconômica brasileira. In: ARILHA, M.; CAETANO, A. J.; GUEDES, M.; MARCONDES, G. S. (Org.). Diálogos 
transversais em gênero e fecundidade: articulações contemporâneas. Campinas: Librum, Associação Brasileira de Estudos Populacionais, 2012, p. 119-130.

DURÁN HERAS, María-Ángeles. Panorama Social de América Latina. Bilbao: Fundación BBVA, 2012.

DURÁN HERAS, María-Ángeles (Org.). La cuenta satélite del trabajo no remunerado en la Comunidad de Madrid. 2. ed. Madrid: Comunidad de Madrid, 2006.

EUROPEAN COMMISSION - EUROSTAT. Household production and consumption. Proposal for a Methodology of Household Satellite Accounts, 2003.

EUROPEAN COMMISSION - EUROSTAT. Gender pay gap statistics. 2018 Available at: http://ec.europa.eu/eurostat/ statistics-explained/index.php/Gender_pay_gap_statistics.

FEIJÓ, Carmem A.; RAMOS, Roberto L. Olinto (Org.). Contabilidade social: a nova referência das Contas Nacionais do Brasil. Rio de Janeiro: Ed. Campus, 2008.

FOLBRE, Nancy. Valuing non-market work. Human Development Report Office. UNDP, Think Piece, 2015.

FONTOURA, N.; PINHEIRO, L.; GALIZA, M.; VASCONCELOS, M. Pesquisas de uso do tempo no Brasil: contribuições para a formulação de políticas de conciliação entre trabalho, família e vida pessoal. Econômica, Universidade Federal Fluminense, v. 12, n. 1, p. 11-46, 2010.

FRIEDAN, Betty. A mística feminina. 1. ed. em português. Petrópolis: Ed. Vozes, 1971.

GEE, Kar-Fai. Development of estimates for household production of non-market services in OECD countries for the index of economic well-being. CSLS, Aug. 2015. (Research Report, 2015-09).

GÓMEZ LUNA, María Eugenia. Satellite account for unpaid household services: an approximation for Mexico. In: THE INVISIBLE economy and gender inequalities: the importance of measuring and valuing unpaid work. Washington D. C.: PAHO, chap. 3.

INSTITUTO BRASILEIRO DE GEOGRAFIA E ESTATÍSTICA - IBGE. Conta Satélite de Saúde: Brasil, 2005-2007. Rio de Janeiro: IBGE, 2009. Disponível em: https://biblioteca.ibge.gov.br/visualizacao/livros/liv43010.pdf.

INSTITUTO BRASILEIRO DE GEOGRAFIA E ESTATÍSTICA - IBGE. As famílias no Sistema de Contas Nacionais. Sistema de Contas Nacionais - Brasil, referência 2010. Nov. 2015. (Nota Metodológica, n. 07, Versão 2). Disponível em: ftp://ftpibge.gov.br/Contas_Nacionais/Sistema_de_Contas_Nacionais/Notas_Metodologicas_2010/0 7_familias_20151110.pdf.

INSTITUTO BRASILEIRO DE GEOGRAFIA E ESTATÍSTICA - IBGE. Outras formas de trabalho 2016. Pesquisa Nacional por Amostra de Domicílios Continua, 2017.

INSTITUTO BRASILEIRO DE GEOGRAFIA E ESTATÍSTICA - IBGE. Estatísticas de gênero: indicadores sociais das mulheres no Brasil. 2018. (Estudos e Pesquisas - Informações Demográficas e Socioeconômicas, n. 38). 
INSTITUTO NACIONAL DE ESTADÍSTICA Y GEOGRAFÍA - INEG. Sistema de Cuentas Nacionales de México: fuentes y metodologías, cuenta satélite de trabajo no remunerado de los hogares. Año base 2013. Disponível em: http://www.inegi.org.mx/est/contenidos/Proyectos/cn/tnrh/doc/SCNM_Metodo_TNRH_B2013.PDF.

JAIN-CHANDRA, S.; KOCHHAR, K.; NEWIAK, M.; YANG, Y.; ZOLI, E. Gender equality: which policies have the biggest bang for the buck? IMF, May 2018. (Working Paper, WP/18/105).

JESUS, Jordana Cristina de. Trabalho doméstico não-remunerado no Brasil: uma análise de produção, consumo e transferência. Tese (Doutorado)-CEDEPLAR/UFMG, jun. 2018.

LIETS, Arne. Let's not lose our thread: only legislation at EU level will ensure fair treatment for garment workers. International Politics and Society, 10 Jul. 2017.

MELO, Hildete Pereira de; THOMÉ, Debora. Mulheres e poder: história, ideias, indicadores. Rio de Janeiro: Fundação Getúlio Vargas (FGV), 2018.

MELO, Hildete Pereira de; CONSIDERA, Claudio M.; Alberto di SABBATO. Dez anos de mensuração dos afazeres domésticos no Brasil. In: FONTOURA, N.; \& C. ARAUJO (Orgs.). Uso do tempo e gênero. Rio de Janeiro: UERJ/SPM/IPEA, 2016.

MELO, Hildete Pereira de; Claudio M. CONSIDERA; SABBATO, Alberto di. Os afazeres domésticos contam. Economia e Sociedade, v. 31, dez. 2007.

MELO, Hildete Pereira de; SERRANO, Franklin. A mulher como objeto da teoria econômica. In: AGUIAR, N. (Org.). Gênero e ciências humanas: desafio às ciências desde a perspectiva das mulheres. Rio de Janeiro: Record, Rosa dos Tempos, 1997.

MICHEL, Andrée. Femmes, sexisme et societés. Paris: Presses Universitaires de France, 1977.

MORANDI, Lucilene; MELO, Hildete Pereira de; DWECK, Ruth H. PIB per capita na ótica de gênero: Brasil, 1991-2015. Faculdade de Economia, Universidade Federal Fluminense, jan. 2018. (Texto para Discussão, n. 335). Disponível em: http://www.proac.uff.br/econ/sites/default/files/uff td335.pdf.

OAKLEY, Ann (1974). Housewife. London: Penguim, 1990.

PERUGINI, Ana. Economia do cuidado: PIB da vassoura. Brasília: Câmara Federal, Comissão de Defesa dos Direitos da Mulher, 2018.

PICCHIO, Antonella. Visibilidad analítica y política del trabajo de reproducción social. In: CARRASCO, C. (Org.). Mujeres y economía: nuevas perspectivas para viejos y nuevos problemas. Barcelona: Icaria, 1999.

SABOIA, A. L.; C. SOARES. Tempo, trabalho e afazeres domésticos: um estudo com base nos dados da pesquisa nacional por amostra de domicílios de 2001 a 2005. Rio de Janeiro: IBGE. Diretoria de Pesquisas, 2007. 47p. (Textos para Discussão, n. 21).

SCHEELE, Alexandra. Gender payback in Europe. Social Europe Dossie. 2017. Available at: https://www.socialeurope.eu/focus/inequality-in-europe. 
SANTOS, C.; A. SIMÕES. Estatísticas de uso do tempo: classificações e experiências nacionais e internacionais. In: SIMÕES, A.; ATHIAS, L.; BOTELHO, L. (Org.). Panorama nacional e internacional da produção de indicadores sociais. IBGE, 2018.

SOARES, Cristiane. Os desafios (para as mulheres do trabalho reprodutivo no Brasil) com o processo de envelhecimento populacional. In: ITABORAI, Nathalie Reis; RICOLDI, Arlene Martinez (Org.). Até onde caminhou a revolução de gênero no Brasil: implicações demográficas e questões sociais. Belo Horizonte, MG: ABET, 2016.

SOARES, Cristiane. A distribuição do tempo dedicado aos afazeres domésticos entre homens e mulheres no âmbito da família. Revista Gênero, v. 9, n. 1, $2^{\circ}$ semestre 2008.

SPONGENBERG, Helena. Only one fifth of tech workers in Europe are women - and the number is declining in Europe's fastest growing industry. IT Girls. International Politics and Society, 10 April 2017. Available at: http://www.ips-journal.eu/storage/regions/europe/article/show/it-girls-1958/.

TEIXEIRA, Marilane Oliveira. Sistema de indicadores de gênero: instrumento para conhecer e reconhecer a experiência das mulheres. In: CARRASCO, Cristina. Estatísticas sob suspeita: proposta de novos indicadores com base na experiência das mulheres. São Paulo: Sempreviva Organização Feminista, 2012, p. 13-30. Disponível em: http://www.ips-journal.eu/about/humanrights/article/show/lets-not-lose-our-thread-2155/.

TRONCOSO, Eugenia Leone. A desigualdade de gênero no mercado de trabalho. In: ARILHA, M.; CAETANO, A. J.; GUEDES, M.; MARCONDES, G. S. (Org.). Diálogos transversais em gênero e fecundidade: articulações contemporâneas. Campinas: Librum, Associação Brasileira de Estudos Populacionais, 2012, p. 79-88.

UNITED NATIONS. The world's women 2015: trends and statistics. United Nations Statistics Division, 2016. Available at: https://unstats.un.org/unsd/gender/worldswomen.html.

UNITED NATIONS. Transforming our world: the 2030 Agenda for sustainable development. General Assembly, 21 Oct. 2015. Available at: https://sustainabledevelopment.un.org/post2015/transformingourworld/publication.

UNITED NATIONS. Declaração e Plataforma de Ação da Mulher da IV Conferência das Nações Unidas sobre a Mulher. Pequim, 1995.

VELAZCO, Jackeline; VELAZCO, Julia. Estimativa do valor econômico do trabalho não remunerado: uma aplicação para o caso do Peru. In: FONTOURA, N.; ARAUJO, C. (Org.). Uso do tempo e gênero. Rio de Janeiro: UERJ/SPM/IPEA, 2016.

WALKER, Kathryn E. Pour la reconnaissance sociale des tâches domestiques des femmes. In: MICHEL, Andrée. Femmes, sexisme et societés. Paris: Presses Universitaires de France, 1977.

WARING, Marilyn. If women counted: a new feminist economics. New York: Harper San Francisco, 1988.

WERNER, Marion; VOSKO, Leah F.; DEVEAU, Angie; PIMENTEL, Giordana; WALSH, Deatra. Conceptual guide to the unpaid work module. Gender \& Work Database, 2007. Available at: http://www.genderwork.ca/gwd/modules/unpaid-work/. 